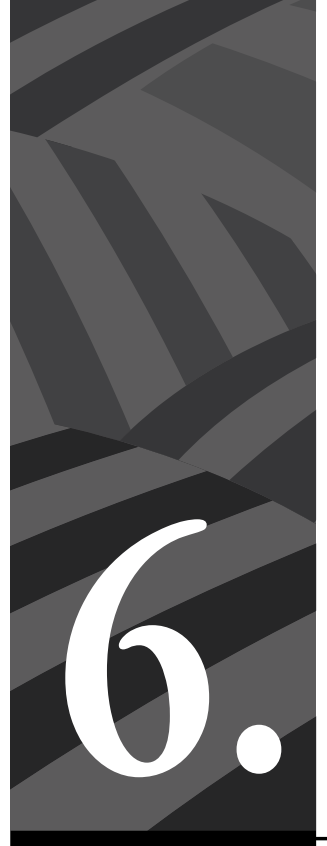

De la diversidad sexual y de género (IGBTI) a las disidencias sexuales, de género y corporales. Tránsitos necesarios e ineludibles 


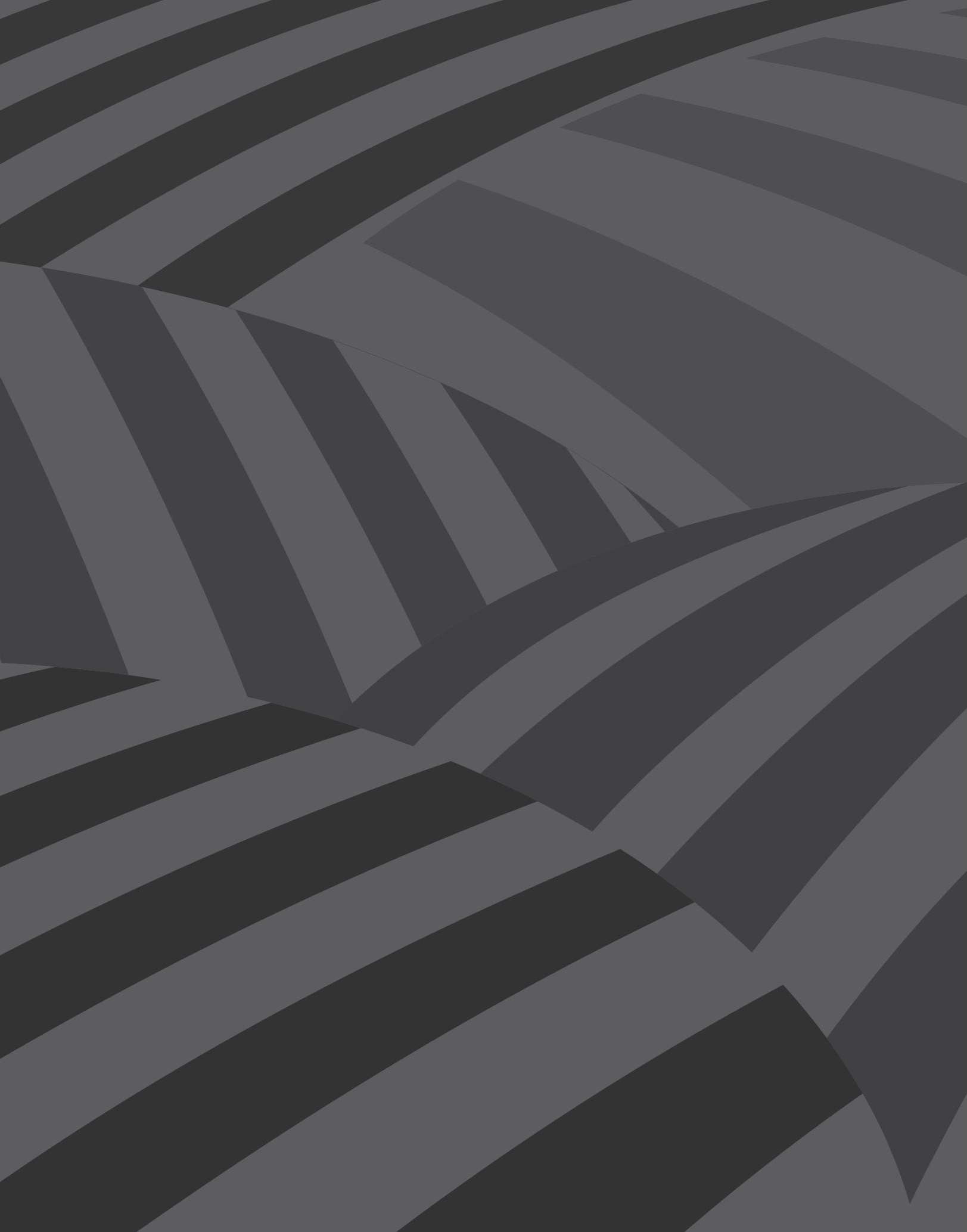




\section{De la diversidad sexual y de género (LGBTI) a las disidencias sexuales, de género y corporales. Tránsitos necesarios e ineludibles}

Por Walter Alonso Bustamante Tejada*

Resumen: En las últimas cinco décadas se han alcanzado logros significativos en el reconocimiento de derechos de los sectores LGBTI, desde una apuesta por la “diversidad sexual y de género". Estos logros se han dado gracias a las políticas sexuales que, mediante reformas para la inclusión, han beneficiado parte de los sectores sociales en mención, sin que se hayan generado transformaciones en el orden heterosexual y patriarcal, en el marco del capitalismo neoliberal. En ese sentido, la diversidad sexual, aunque ha posibilitado logros, también ha mostrado sus limitaciones. En este artículo se evidencian algunas de esas limitaciones y se plantean las "disidencias sexuales, de género y corporales”, como alternativa para retomar luchas de manera articulada, parafraseando a Wittig, "con muchos otros diferentes, todas las mujeres y numerosas categorías de hombres" (2006, p. 53), para pensar y actuar por cambios estructurales.

Palabras clave: diversidad sexual y de género, disidencias sexuales, de género y corporales, políticas sexuales, derechos humanos LGBTI.

\section{From Sexual and Gender Diversity (LGBTI) to Sexual, Gender and Corporal Dissidences. Necessary and Unavoidable Transitions}

Abstract: Significant achievements towards the recognition of rights of LGBTI segments have been reached over the last five decades, from the perspective of "sexual and gender diversity". Within the scope of sexual policies through reforms for the inclusion, these achievements have benefited part of the aforementioned social segments, without transforming the heterosexual

* Historiador Universidad Nacional de Colombia. Magíster en Estudios de Género y Cultura en América Latina, Universidad de Chile. Candidato a doctor en Estudios de Género, Universidad Nacional de Córdoba, Argentina. Docente investigador de la Maestría en Educación y Derechos Humanos de la Universidad Autónoma Latinoamericana (UNAULA); coordinador de la línea de investigación Feminismo, Género, Interseccionalidad y Sujetos Políticos. Correo electrónico: walonso23@gmail.com 
and patriarchal order in the framework of the neoliberal capitalism. In that sense, sexual diversity, though providing achievements, has also shown its limitations. In this article, we show some of these limitations and we propose the "sexual, gender and corporal dissidences" as an alternative that resumes the struggles in an articulate way, with many other different people, women and various men categories, in order to rethink and take action for structural changes.

Keywords: sexual and gender diversity, sexual, gender and corporal dissidences, sexual policies, LGBTI human rights.

Cómo citar este artículo: Bustamante Tejada, Walter Alonso (2020). De la diversidad sexual y de género (LGBTI) a las disidencias sexuales, de género y corporales. Tránsitos necesarios e ineludibles. Revista Controversia, 215, 201-234.

Fecha de recepción: 17 de marzo de 2020

Fecha de aprobación: 20 de julio de 2020

\section{Introducción}

comienzos del siglo xxI, en mi primera investigación, hablé de
homosexualidad. Su abordaje histórico me permitió aprender
que esta era una forma de nombrar desde la mirada médica, como síntesis de la articulación de las instituciones ordenadoras del cuerpo y la sexualidad. Al continuar mi proceso de aprendizaje desde los derechos humanos, y en el encuentro con los activismos, incursioné en la denominación "diversidad sexual y de género" para hablar de experiencias, identidades, prácticas en relación con la población LGBTI; la diversidad sexual podía explicarse en relación con la norma heterosexual y como término sombrilla de esas identidades (Núñez, 2011), o también como alternativa contraidentitaria y contrauniversalizante que puede pretender la sigla.

En la segunda década del siglo, mientras avanzaba en mi reflexión crítica en torno a las agendas de la diversidad sexual y de género orientadas al reconocimiento, emergieron en el contexto local, en la ciudad de Medellín, experiencias que hablaban de disidencia sexual, tomando distancia de esas agendas con las cuales sentía inconformidad. De ahí 
partió mi interés por entender quiénes, a qué y/o con qué interés, nombrar la disidencia en relación con el cuerpo, el género y la sexualidad.

Entiendo y asumo que esas formas de nombrar responden a procesos históricos que no son vacíos o carentes de sentido, por el contrario, dan cuenta de los lugares desde los cuales nos ubicamos en el mundo, en las relaciones, a las realidades que pretendemos generar y a los ideales de sociedad a que aspiramos. Porque denominar, nombrar, no es un acto simple, banal, es un asunto político y requiere de responsabilidad histórica y reflexión.

Sin embargo, considero que en el campo de los estudios sobre el cuerpo, el género y la sexualidad, parece que viviéramos en una carrera desaforada por producir categorías y formas de nombrar prácticas, identidades y procesos de subjetivación; esto, con un interés permanente por escapar de algo que es irremediable, los límites que impone el lenguaje, porque querámoslo o no, como lo ha señalado Judith Butler, "la denominación es a la vez un modo de fijar una frontera y también de inculcar repetidamente una norma” (2002, p. 26). En esa carrera hay, a su vez, un interés por evidenciar mayor criticidad, distanciamiento de lo hegemónico, una propuesta de algo novedoso y alternativo, o la búsqueda por recoger y dar lugar a la mayor posibilidad de experiencias, anhelo que siempre será insuficiente.

Este artículo es un ejercicio de consolidación de una síntesis de intuiciones, ideas, reflexiones y algunas piezas a partir de las cuales armar y sustentar la categoría “disidencias sexuales, de género y corporales” de manera situada, porque "la estigmatización y exclusión de los disidentes sexuales aparece en todo el mundo, aunque las formas de representación y resistencia son localizadas culturalmente” (González, 2016, p. 180); categoría, no como un fetiche, no como sinónimo de "diversidad sexual y de género", no como identidades y mucho menos como diferencias vinculadas al cuerpo, el género y la sexualidad de manera aséptica. La asumo como una forma de nombrar unas apuestas políticas 
y como herramienta de posición política frente a la vida, es decir, de posicionamiento en las relaciones de poder que emergen de cuerpos marcados y violentados por la acción de diferentes sistemas, que constituyen lo que Patricia Hill Collins denominó “matriz de dominación” (2000, p. 299), cuerpos sexualizados, racializados, empobrecidos, entre otros; categoría que a su vez es útil para el análisis, la acción y la generación de conocimiento.

Desarrollo mis planteamientos en tres partes. En La diversidad sexual, límites y limitaciones, planteo algunos acontecimientos de carácter local y nacional que permiten observar los límites que establece la diversidad sexual y las limitaciones con que cuenta la categoría, las cuales se ven reflejadas tanto en las miradas sobre la realidad, en las apuestas políticas que ha hecho, como en las jerarquías de derechos entre las identidades representadas en esa diversidad. En Derecho, derechos humanos y homonormatividad, realizo una aproximación crítica a la función que han cumplido el derecho y los derechos humanos en los procesos de asimilación y normalización de las diversidades, como expresión de esos límites y limitaciones. Finalmente, en Un nuevo pacto: disentir activa, colectiva y solidariamente, expongo lo que entiendo por disidencia sexual, de género y corporal, los sujetos de esta, así como los mecanismos para la acción y los retos que implica desde lo colectivo, lo solidario y el análisis interseccional.

\section{La diversidad sexual, límites y limitaciones}

Que se casen con el gato si quieren, pero yo nunca luché por el casamiento gay. Vengo de otro tiempo que cuestionaba la burguesa postal familiar. Éramos locas feministas, anarcas que peleábamos por la liberación de ese tipo de instituciones. Ya había pasado la política del emparejamiento de iguales. Por eso sospecho de este destape con portaligas. (Lemebel, García y Arroyo, 2019, p. 71). 
La mencionada diversidad sexual y de género ha sido útil en el proceso histórico de reconocimiento de los sectores LGBTI y sus derechos, pero considero que ha perdido fuerza crítica, autocrítica y capacidad de incidencia para transformaciones estructurales, en la medida que los y las voceras de esos sectores, como lo plantea Gabriela González Ortuño "defienden su derecho a pertenecer al orden creado desde la modernidad heteropatriarcal capitalista” (2016, p. 195), o en palabras de Norma Mogrovejo, es un movimiento "que devino en una búsqueda hacia una integración epistémica” (2008, p. 69). Para plantear los límites y limitaciones de la diversidad sexual, presento tres bloques temáticos: el primero a partir de experiencias testimoniales de carácter local, que más que meras anécdotas dan cuenta de la materialidad de los debates teóricos que quiero plantear, y los dos siguientes desde procesos de carácter nacional y su incidencia mediática, uno orientado a señalar los procesos de asimilación desde la diversidad y el otro a plantear la jerarquización de identidades, necesidades y agendas que ha establecido la perspectiva de la diversidad.

\subsection{Diversidad y disidencias, desencuentros desde lo local}

El lunes 28 de abril de 2014, en el extinto programa Calle Arco Iris del canal Telemedellín en Internet, dedicado a abordar temas en torno a la "diversidad sexual y de género", se presentó una entrevista con los realizadores de Némesis Time, una guía gay de la ciudad, que como tal se dedica principalmente a publicitar los sitios comerciales de divertimento para personas de las poblaciones LGBTI. En dicha entrevista se le preguntó a uno de los realizadores de la guía acerca del asesinato de una mujer trans, hecho que había ocurrido por esos días en el centro de la ciudad; su respuesta planteó como explicación, "que ella se dedicaba a la prostitución", con lo que terminaba justificando su muerte por el oficio a que se dedicaba. Respuesta desafortunada que quedó ahí y no trascendió, pero que sí registré en mis notas. 
Meses después, desde ese mismo magacín se señaló al Colectivo DeFormación como "vándalos y delincuentes", por su forma de participación en la Marcha Anual de la Diversidad Sexual y de Género de Medellín. Ese año, personas del Colectivo y otras participantes de la marcha habían hecho pintas o grafitis en distintos sitios, por lo cual los organizadores de la "movilización", hombres gais predominantemente, les instaron a retirarse de esta porque "dañaban la marcha”. Debo señalar que tradicionalmente gran parte de la logística de este evento se realiza con recursos que entrega la Administración Municipal; además, se convoca a las diferentes instituciones oficiales a respaldarlo, hacer presencia y velar por su buen desarrollo, con lo cual más que una marcha ciudadana autónoma e independiente y lo que esto implica, lo que se lleva a cabo es un desfile, incluso con la aspiración de sus organizadores de venderlo como un "evento turístico de ciudad”, lo que daría indicios de su “inclusión”.

$\mathrm{Y}$ es que, en la segunda década del siglo $\mathrm{xx}$, surgieron en la ciudad de Medellín algunos colectivos y espacios de estudio y acción crítica en torno a los cuerpos y las sexualidades, que planteaban su distancia frente a los discursos de la diversidad sexual y de lo LGBTI, y su cercanía con diferentes sectores sociales que trabajan desde problemáticas de exclusión, vinculadas a lo económico, lo social, lo cultural y a los derechos humanos de diferente generación. Algunos de esos espacios se nombraron DeFormación, Colectivo Apostasías y Leonas Porno Proletarias, que para el año 2015 se articulaban bajo la denominación Bloque Disidente.

En su momento, los procesos de reflexión y de acción en el espacio público tanto por parte de DeFormación como del Bloque Disidente permitían airear, pensar otras formas, evidenciar y cuestionar que las luchas LGBTI no buscaban transformar de manera profunda nuestra sociedad, ni se preguntaban por un modelo de esta, diferente a aquella en la cual no se cuestionen privilegios independientes de ser LGBTI, que además es agotada por la hegemonía gay. Donde vale afirmar que, “los gays (...), están interesados en transformar y ser incluidos en la cultura hegemónica 
de la ciudad, o sea, que la sexualidad o la transgresión del género no acarree la exclusión y el rechazo social que aún siguen soportando" (López, 2014, p. 202).

Afirmación que aplica para el gay que justifica la muerte de una mujer trans por estar en ejercicio de prostitución; para los líderes que expulsan a quienes "dañan la marcha soñada”; pero también para quienes se rasgan las vestiduras al ver los cuerpos que, por la gracia del carnaval, se atreven a aparecer desnudos en las calles de la ciudad e incluso a aclarar al público que quienes marchan "no me representan”. Y, por qué no, tiene que ver también con las luchas por ser incluidas como personas decentes, dentro del modelo de la vetusta institución familiar, como se verá más adelante.

Es precisamente por el interés de adquirir y conservar privilegios a partir de un discurso que demanda reconocimiento e inclusión, que se puede explicar por qué las luchas del movimiento LGBTI de Medellín no han sido, o lo han sido tardíamente, las luchas de las mujeres, de las víctimas del conflicto armado, de afrodescendientes e indígenas. $\mathrm{Su}$ objetivo prioritario ha sido: inclúyanme en la cultura hegemónica, vean que no soy ofensivo para el Sistema, vean que soy una buena persona y aporto de manera efectiva al mercado. El principal mecanismo local para conseguirlo ha sido una política pública identitaria.

En relación con la categoría gay, es necesario enunciar algunas tensiones que plantea su devenir: en un primer momento, reconocer su emergencia e importancia en el contexto de las luchas visibilizadas y potencializadas en torno a las revueltas de Stonewall, en 1969, en New York, las cuales tenían unas aspiraciones ya olvidadas y que se recordarán al traer la memoria de la Liga Estudiantil Homófila; en segundo lugar la categoría se asocia, desde una lectura del despliegue neoliberal de los años ochenta, también en Estados Unidos, a su afectación de la noción de ciudadanía, vinculada a la posibilidad de incursión y circulación en el mercado, con prácticas sociales y económicas asociadas a los lugares 
y las marcas que consumen sus integrantes y sus sitios para la rumba, lo cual está ligado con el estatus que como categoría quiere lograr; en tercer lugar, en nuestro contexto local, esta categoría ha sido apropiada, incluso desde sectores populares, como eufemismo, tomando distancia de términos agresivos como loca o marica, vinculados principalmente a sectores empobrecidos y periféricos, y que no deja de marcar diferencias en torno al prestigio, haciendo que sea una categoría que se asocie al "modelo etnicista" representado en el varón, clase media y blanco (Borrillo, 2011), pero que se materializa de formas diferentes en los contextos y estratos sociales de la ciudad, con un aire finalmente de conservadurismo y buena reputación.

\subsection{La inclusión en la cultura y la moral hegemónica}

En el contexto colombiano y en esos mismos años, el 4 de noviembre de 2015 la Corte Constitucional aprobó la adopción universal por parte de parejas del mismo sexo. La noticia tuvo espacio en la radio, la prensa, la televisión y las redes sociales, porque era importante según se viera, para los derechos de los niños y niñas, los derechos de la población LGBTI y para la materialización jurídica del Estado social de derecho, o una derrota para las mayorías cristianas que luchan por la conservación de valores y tradiciones que chocan con el reconocimiento de las libertades, la dignidad y la autonomía de la ciudadanía en su relación con el Estado.

Desde ese momento, la misma Corte aplazó semana a semana la decisión sobre el matrimonio igualitario, que en su recta final vivió dos momentos importantes: el 7 de abril de 2016 rechazó, con votación de 3 a 6, una ponencia negativa, y el 29 de abril, con votación de 6 a 3, aprobó el matrimonio igualitario mediante Sentencia de Unificación 214.

Mientras se dieron los aplazamientos, en las redes sociales se difundieron miradas y opiniones a favor o en contra del tema. En ese contexto, el 6 de febrero circuló por redes un artículo titulado: “Las 20 parejas 
homosexuales más estables"; el objetivo era validar la existencia de parejas del mismo sexo por su durabilidad, quizá ante argumentos como la inestabilidad de estas. Luego de su publicación, un primer comentario sobre el artículo fue: "Esto es dar ejemplo”, lo que considero que es indicador de la instalación de una nueva moralidad sobre la vivencia de la sexualidad por parte de parejas del mismo sexo, precisamente desde la construcción política de esa categoría de "sexo" y en completo vínculo con la aprobación de la norma, pues

el derecho es un instrumento de articulación del sistema patriarcal. A través de este se regulan las conductas de hombres y mujeres hacia un determinado modelo de convivencia, el patriarcal, y se modelan las identidades de género de forma tal que respondan a las funciones ideológicamente asignadas a hombres y mujeres. El derecho se entrama en otros sistemas normativos (social y moral) que, al igual que éste, contribuyen al disciplinamiento del género. (Facio y Fries, 1999, p. 35).

De esta manera, "la homosexualidad es funcional al sistema de género en tanto que hace del género del compañero/a sexual una barrera de selección. No supera al género, sino que lo reproduce” (Moreno y Pichardo, 2006, p. 150), contrario a lo que plantea Daniel Borrillo, cuando afirma que "el movimiento LGBT produjo el triunfo de una visión 'contractualista' y desacralizada de la vida familiar” (2011, p. 41), lo cual podría haber sido más bien un ideal.

Siguiendo a Facio y Fries (1999), articulación, regulación, modelación y disciplinamiento son cuatro verbos que dan cuenta del derecho como bisagra en la función de subjetivar y demarcar las relaciones, generando dispositivos y condiciones de verdad, que indican lo posible y lo permitido mediante dos sistemas normativos: el social y el moral, que permean la vida cotidiana para el cumplimiento de un deber ser y la emergencia de un tipo de sujeto y de sexualidad. 
Es allí donde radica la fuerza de la afirmación "esto es dar ejemplo”, que valida el matrimonio igualitario desde la noción de pareja y familia patriarcales, y demanda la asunción de valores morales tradicionales: monogamia, permanencia y larga duración, en fin, “estabilidad de pareja”, salvaguardados por el derecho, que hace que algunos sujetos se constituyan en nueva norma, con la consecuente descalificación que "puede llevar, como de hecho ocurre, a una condena moralista de la sexualidad libre, entendiendo como tal las críticas a la promiscuidad, al sexo por el sexo” (López C., 2015, p. 145), generando fraccionamientos en los sectores al establecer modelos de identidad y exclusión de vivencias, pues "los sujetos jurídicos siempre se construyen mediante ciertas prácticas excluyentes que, una vez determinada la estructura jurídica de la política, no «se perciben»" (Butler, 2001, p. 34).

El matrimonio, como institución “intrínsecamente patriarcal” (Borrillo, 2011), ha sido cuestionado por el feminismo anarquista y su promoción de la libertad como principio rector, donde la relación entre sexos debería ser absolutamente libre; también por las feministas lesbianas al problematizar la heterosexualidad, y señalar la relación de dominaciónexplotación de las mujeres y sus cuerpos. En ese mismo sentido, aun a pesar de lo novedoso de las normas, los modelos sexuales y de género están vinculados al contrato sexual explicado por Pateman (1995), sobre el cual se soporta nuestro actual patriarcado fraternal, que es heteronormativo y se materializa en el Estado y la familia patriarcal, institución validada mediante la figura matrimonial y la dicotomía sexo-genérica. Andamiaje fundado sobre una ideología sexual, y una institución que más que un contrato trae consigo el mantenimiento y permanencia de unos valores morales tradicionales, que no tendrán que ser obligatorios pero que se asumen como tales, y que, al incorporar las parejas formadas por personas del mismo sexo, se renueva como mecanismo de control social "para el mantenimiento del orden político, económico y social del Estado Liberal” (López C., 2015, p. 140). 
En medio de la euforia que produjo el rechazo de la Corte a la ponencia negativa sobre el matrimonio igualitario y la consecuente aprobación que esta traería, en una de las noticias publicadas ese 7 de abril se señaló: “La Corte Constitucional avaló el matrimonio igualitario en Colombia, considerado este como el último asunto que hacía falta para que la comunidad Lgbti tuviera plena igualdad en el país” (El País, 2006).

Hay en ese anuncio dos afirmaciones erróneas: la primera, considerar que el matrimonio era "la meta" y una expectativa para "toda" la población agrupada bajo la sigla LGBTI, como si fuera una comunidad homogénea y uniforme, acorde quizá con el interés reontologizador del sujeto, que renueva su ciudadanía integrando en ella el cuerpo, el género y la sexualidad (Sabsay, 2011). Pero no es así, para otros sectores son otras las necesidades, demandas y logros para la materialización de su ciudadanía. Matrimonio y adopción han sido banderas de la agenda gay y lésbica principalmente, a los cuales también sería pertinente hacer un análisis de sexo, clase y raza, para dar cuenta de si en realidad es prioridad incluso para todas las lesbianas y todos los gais. Así,

el matrimonio podría llegar a percibirse por la sociedad, como de hecho está ocurriendo, como la meta del movimiento LGTB. Es decir, conseguida una ley de matrimonio entre personas del mismo sexo junto a un grupo de derechos destinados a asegurar la no discriminación por orientación sexual, podría parecer que ya no hay nada más por lo que luchar, y podría dar argumentos a los grupos conservadores para detener la lucha por la emancipación sexual en general y contra la homofobia social en particular. (López C., 2015, p. 142).

El segundo error es considerar que con la aprobación del matrimonio igualitario se accedía a la igualdad plena. Esto nos pone frente a las distancias entre lo formal y lo abstracto del derecho, pues, mientras en efecto quienes deseen acceder al convenio marital pueden hacerlo en uso de esa igualdad que reconoce la norma, esta se ve enfrentada a los obstáculos que interponen los operadores que no reconocen la 
igualdad de estas parejas, como sucedió con el juez décimo civil municipal de Cartagena, Ramiro Flórez Torres, quien se negó a casar a dos mujeres el 31 de agosto de 2020, e incluso en su momento en relación con la adopción, con iniciativas como la de la entonces senadora Vivian Morales —del Partido Liberal como Parmenio Cárdenas, quien penalizó la homosexualidad en Colombia en 1936 - para revertir la norma, al promover la realización de un referendo para definir que la adopción solo podría ser por parte de parejas heterosexuales constituidas; o el déficit de igualdad que expresan los altos índices de discriminación y violencia hacia la población que adquirió ese derecho. Es decir, quien quiera casarse puede hacerlo, es su derecho; otros, otras, otres deben seguir batallando en su cotidianidad para que no se les expulse de su hogar, de la escuela, del trabajo, del espacio público, para no ser objeto de agresiones contra su vida y su integridad, porque la igualdad se juega su lugar entre lo formal y lo abstracto. De lo contrario, se llega solo a

un pseudoprogresismo que se conforma con el acrítico festejo de las políticas de identidad, y que pretende conformar con ideales de equidad a todos aquellos ya configurados y fijados como Otros, colocándolos de este modo en su módico y modesto lugar dentro de la sociedad. (Sabsay, 2011, p. 37).

Esas identidades dispersas, ahora moderadas y fácilmente reguladas, son incluidas en unas estructuras de pensamiento y representación de las identidades aceptables, sin que con ello haya que cuestionar nada del orden ya establecido, pues como

reivindicaciones hacia el "matrimonio" y la igualdad de derechos, estas tendencias se enmarcan en una defensa de la "preferencia sexual" y de la "tolerancia”, y en una búsqueda de reconocimiento por parte de la sociedad heterosexual. Se perfilan por tanto como luchas por la libertad individual y la integración que, aunque importantes, no cuestionan de fondo el sistema social. (Falquet, 2006, p. 16). 
En otra dirección, mientras que la heterosexualidad implica y requiere la interdependencia económica y la consabida explotación de las mujeres mediante el contrato matrimonial, el capitalismo posibilita la identidad gay, que por la capacidad y solvencia económica no requerirá la interdependencia; esto permite observar que "la indisolubilidad de la homonormatividad y la heteronormatividad se basa en el androcentrismo de sus presupuestos, consecuencia de la planificación masculina de las políticas de la sexualidad” (Moreno y Pichardo, 2006, p. 152). Así pues, la inclusión no implica la transformación de las estructuras de género e instituciones patriarcales, como la constitución de pareja y el matrimonio, sino la asimilación por parte de los sujetos para ser tenidos en cuenta dentro de la estructura.

\subsection{Jerarquías y subalteridades en el marco de las políticas sexuales}

Antes de los avances relacionados con la adopción universal y el matrimonio igualitario, la Corte también aprobó derechos significativos para las personas intersexuales y transexuales. Estos se han dado de manera más silenciosa, sin tanta divulgación en los medios de comunicación ni explosiones de alegría, factor que da cuenta de las relaciones de subalteridad y hegemonía entre las agendas o del juego de mayorías y minorías al interior de una "minoría substantiva”. También hay que ver allí la expresión de la biopolítica, en su función de controlar los cuerpos mediante la normalización ya no por el bisturí y en manos del poder médico, sino por la acción performativa de la norma y del documento público que materializa la acción del Estado.

En el año 2013 se omitió la asignación de una identidad sexual como niño o niña a un bebé nacido con lo que desde la medicina dicotómica se denomina ambigüedad genital, lo que implicó que no existiera jurídicamente y quedara por fuera de la protección del Estado. A partir de este caso la Corte Constitucional, mediante Sentencia T-450A, ordenó a la Registraduría General de la Nación que las personas que nazcan con 
ambigüedad genital puedan ser registradas como indefinidas hasta que tengan la capacidad de decidir sobre su cuerpo. Porque el Alto Tribunal considera que el cuerpo intersexual, expresión de la biología, es algo transitorio, y se espera que en el futuro las personas asuman una identidad dicotómica. Es decir, todo cuerpo ha de tener carta de existencia por parte del Estado, aun reconociendo su característica ambigua, pero no como posibilidad, sino como un cuerpo a normalizar.

En relación con las personas transexuales, a comienzos de 2015 la Corte, en Sentencia T-063, reafirmada por el Decreto 1225 del Ministerio del Interior y Justicia, concedió la posibilidad de "corrección del componente de sexo" a las personas transexuales, al señalar que la incoherencia que ellas manifestaban entre su identidad de género y sus características biológicas se debía a un error de quienes les habían asignado la identidad sexual al momento de nacer, según parámetros dicotómicos de sexo y género. Es decir, se asume de manera formal y como un derecho, la separación entre sexo biológico e identidad de género en la construcción subjetiva de la identidad. Sin embargo, como se verá a continuación, esto no garantiza el interés de la norma.

Daniela García, activista y politóloga transexual de la ciudad de Medellín, ha vivido los procesos que le permiten las sentencias expedidas para las personas transexuales. En entrevista que me concedió el 16 de marzo de 2016 manifestó:

Después de haber cambiado la cédula, el nombre, el sexo, el número, (...) La cédula no me va a garantizar que alguien no me violente en la calle por el cambio, porque generalmente la gente tiene un imaginario negativo contra las mujeres trans, entonces partiendo de esa idea no van a estar mirando la cédula para agredirte (...) Desde el tema del género no se me está reconociendo como tal mi identidad propia, sino que simplemente me reconoce mi posición social con respecto a que me asumo desde lo femenino. 
El logro está en el acceso a una nueva documentación que reconozca las decisiones del sujeto político para el ejercicio de su ciudadanía y que lo mantenga bajo la salvaguarda de la institucionalidad; sin embargo, la norma no afecta la injusticia cultural y simbólica que permite la discriminación y la violencia. Por otro lado, Daniela afirma que aun a pesar de lo logrado, su identidad solo se acepta ajustada a lo establecido dentro de lo femenino, en sus representaciones y su lugar entre las márgenes dicotómicas y jerárquicas del género, y no en tránsito permanente.

Y es que la inclusión, unida al asimilacionismo, en el caso de las mujeres trans provoca una presión constante para tener un cuerpo, senos, cabello largo, en una lucha por determinar quién es más mujer. Porque:

Aunque nadie obligue a las transexuales a que se sometan a terapias hormonales, electrólisis o cirugía, las alternativas a su alcance son innegablemente forzadas: (...) "Dada la prescripción patriarcal de que una persona debe ser masculina o femenina, la libre elección está condicionada”. (West y Zimmerman, 1999, p. 140, cita de Raymond, 1979).

Porque ante la ausencia de otros modelos y la vigencia solo de aquellos apropiados desde la infancia, la persona transexual se mueve en la dinámica de ser masculina o femenina como está establecido. Es decir, es un tránsito que se vive siempre dentro de la norma dicotómica heterosexual, cuando "entre las mujeres y los hombres hay millones de posibilidades del ser, así como entre el bien y el mal” (Gargallo, 2008, p. 25).

Así pues, según lo expuesto, los avances en el reconocimiento de derechos implican nuevas tecnologías sexuales para el control de los cuerpos, las cuales reorganizan exclusiones por los nuevos estándares de ciudadanías que se validan y dan cuenta de la relación entre agendas hegemónicas y subalternas al interior de los sectores LGBTI. En palabras de Fraser, se sustituye la transformación social por la "ingeniería identitaria" (2000, p. 67). 


\section{Derecho, derechos humanos y homonormatividad, una aproximación crítica}

Después sacaste una ley que me discrimina a mí, después sacaste otra ley que me legitima a mí, a mí no me des permiso porque no te lo pedí.

(Susy Shock, 2019)

Considero que la diversidad permite la posibilidad de reconocer diferencias, sumarlas, sin que se cuestionen y afecten estructuras de manera significativa, pues no trae consigo la necesidad de toma de posición crítica frente a los modelos, poderes, verdades y relatos hegemónicos. No pasa de ser un eufemismo como decir que es riqueza, ante lo cual la estrategia ha sido principalmente la de la aceptación, el asimilacionismo, la normalización y el adecentamiento desde la noción de "inclusión”, mediada por el "multiculturalismo" e incluida desde las políticas del reconocimiento, según la perspectiva de Nancy Fraser, quien las denomina "modelo de la identidad" (2000, p. 58).

En términos de sexualidad y género, ha servido positivamente para el reconocimiento de la variedad de posibilidades entre los seres humanos, en lo que tiene que ver con el cuerpo, la orientación sexual, las expresiones corporales, de género y la identidad de género; además como algo diferente frente a la norma heterosexual, pero sin que sea necesario cuestionarla, porque no implica de por sí una resistencia o planteamiento alternativo, por lo cual esta queda intacta y más bien "promete la posibilidad de un electorado gay desmovilizado y una cultura gay privatizada y despolitizada anclada en la domesticidad y el consumo” (Duggan, 2002, p. 179, en López C., 2015, p. 138).

Además, no tiene en cuenta otros factores que afectan los niveles de vulnerabilidad de las personas, y genera más bien, desde ese modelo de la identidad, formas hegemónicas y/o estereotipadas de ser L-G-B, $\mathrm{T}$ e I, precisamente desde quienes gozan de más privilegios y no han experimentado necesariamente las violencias que esto implica. Porque, 
además, la diversidad se asume como "lo otro" sobre lo cual se ha hecho énfasis y que emerge frente a esa norma, como lo recita Susy Shock (2019), "vos y yo somos distintos, somos distintas las dos, pero crees que solamente la diferente soy yo".

Para llevar a cabo estos procesos han sido de suma utilidad el derecho, los derechos humanos y las políticas sexuales, con el fin de lograr la "inclusión" y hacer que la diversidad no sea algo molesto. En la ciudad de Medellín, "ha servido sobre todo, para implementar políticas públicas relacionadas con los derechos sexuales y reproductivos. Sin embargo, ese uso ha hecho perder de vista el valor político de la resistencia a un sistema heteronormativo" (Mogrovejo, 2008, p. 63). En este orden de ideas, la "inclusión" ha consistido, como ya se observó con el matrimonio igualitario, en la asimilación a las formas de nombrar y a las instituciones patriarcales tradicionales, mediante las cuales se han reglamentado las relaciones erótico-afectivo-amorosas y las identidades de género de los sujetos. Por tanto, la inclusión ha traído posibles beneficios a los sujetos de esas políticas, pero no ha afectado suficientemente las estructuras a las cuales los sujetos "diversos" se han acomodado mayoritariamente, sin necesidad de remover de su lugar, por ejemplo, la homofobia de Estado, el racismo, el clasismo, el sexismo y las violencias derivadas de la matriz de dominación heteropatriarcal.

Para estos planteamientos, me ubico desde una crítica feminista del derecho y del sujeto del derecho; desde allí se señala al derecho como una institución patriarcal que se adapta a las épocas, en la cual el avance en las transformaciones que de él se esperan no implica el abandono de esa característica histórica, por tanto, las reformas desde el "litigio judicial y el lobby" deben observarse críticamente, pues utilizar ese derecho legitima y valida las formas de relaciones de poder en que interviene, y confiar en el paradigma del derecho es sostener el paradigma patriarcal, donde "esta concepción del derecho conduce a una visión mucho menos optimista sobre las posibilidades de reforma legal" (Olsen, 2000, pp. 37-38). 
Por otro lado, y desde la propuesta de Daniel Borrillo vinculada a pensar una teoría queer del derecho, se señala:

La lógica binaria de los sexos, aparece como el soporte del sistema jurídico tanto a nivel individual cuanto familiar y social. De hecho, durante siglos fue esta misma lógica la que sirvió para justificar la inferioridad de la mujer y hoy día, sigue sirviendo para legitimar la desigualdad de lesbianas, gays y transexuales. (2011, p, 37).

Utilizo también la propuesta de Leticia Sabsay (2011), quien plantea que en Argentina, al aprobar la ley de matrimonio igualitario y la ley de identidad de género, se evidencia que las personas en ejercicio de prostitución, especialmente población trans, son quienes aún no logran el reconocimiento pleno de la ciudadanía. Para hacer su crítica, Sabsay desarrolla la hipótesis según la cual "la reinterpretación liberal de las visiones constructivistas sobre la identidad y el sujeto de género limitarán su potencial crítico” (2011, p. 32), hipótesis que comparto y desde la cual quiero argumentar, pues las políticas sexuales y el "modelo de identidad" se orientan al fortalecimiento de una homonormatividad y a la "reontologización del sujeto del liberalismo". Donde "homonormatividad es un concepto acuñado para referirse a la construcción de un modelo normativo, pretendidamente hegemónico, de sujeto gay/ lesbiano, dentro del proceso de normalización de lo que podríamos llamar cuestión homosexual en las sociedades occidentales" (López C., 2015, p. 138).

Insiste Sabsay en que el creciente interés por el reconocimiento a expresiones de la sexualidad y el género se constituyen en "formas de regulación sociosexual”, pues las dinámicas de inclusión y reconocimiento se dan sobre la normalización de las sexualidades, que como se observó, generan la emergencia y visibilización de las que se alejan del estándar o quedan en la parte baja de una nueva pirámide de la sexualidad o el género. Procesos que se viven en un momento en que la sexualidad da cuenta del nivel de democracia alcanzado por una sociedad. Donde, 
la democracia sexual, entendida en términos de políticas de equidad de género y reconocimiento de la diversidad sexual y de género, aunque loable en sus ideales, no es ajena a la rearticulación de cierta jerarquía sociosexual, en la que junto al heterocentrismo imperante, se generan nuevas homonormatividades en las que la familia y la pareja como modelos hegemónicos de organización social siguen siendo centrales. (Sabsay, 2011, p. 32).

En ese proceso de reontologización del sujeto del liberalismo, se genera una nueva representación de la relación sexo/género, rota en la medida que se desdibuja el binarismo, que insiste en mantener niveles de normalización y estandarización. La reontologización implica la recuperación de un estado de naturaleza previo a la ley, la búsqueda en estos nuevos sujetos de una bondad por decirlo así, una validez, pero no la posibilidad de emergencia precisamente en confrontación con la ley (Butler, 2001, p. 35). Para esto, la experiencia trans es importante porque es una experiencia que da cuenta de la "paradoja de la sujeción (assujetissement) es precisamente que el sujeto que habría de oponerse a tales normas ha sido habilitado, si no ya producido, por esas mismas normas” (Butler, 2002, p. 38). En todo esto,

¿cuál es el rol o los roles que los aparatos gubernamentales están asumiendo en la definición de nuestros ideales, los cuales siguen discriminando entre prácticas e identificaciones más o menos legítimas, entre respetables y menos respetables gays, entre aceptables e inaceptables disidentes sexuales, entre buenos gays y malos queers? (Sabsay, 2011, p. 74).

Esa es la función para la cual se diseñan esos aparatos gubernamentales: para la regulación que visibiliza los nuevos excluidos, sectores que no alcanzan índices de aceptabilidad.

Ante esta realidad el derecho promueve el asimilacionismo, pues las mujeres deben asimilarse a las instituciones y formas masculinas para ser reconocidas, además "en la actualidad la igualdad se juzga comparando a las mujeres con los hombres” (Olsen, 2000, p. 35). Lógicas que 
se extienden hasta la diversidad sexual y de género, la cual se incluye desde modelos heteronormativos sobre el cuerpo y la sexualidad:

El efecto general es el de imponer una identidad de grupo única y drásticamente simplificada que niega la complejidad de las vidas de las personas, la multiplicidad de sus identificaciones y de las fuerzas entrecruzadas que operan en sus diversas afiliaciones. (Fraser, 2000, p. 60).

En relación con los derechos humanos, estos han sido fundamentales para la superación de las inequidades, pero igual han proveído un modelo tradicional de ciudadanía, por lo cual su logro se constituye en tecnología de una nueva biopolítica, ante lo cual es pertinente la pregunta acerca de " ¿cómo pensar incluso en los derechos mismos por los que luchamos como una forma de regulación más?” (Sabsay, 2011, p. 24). Y es que tal como lo plantea Norma Mogrovejo, retomando a Yuderkis Espinosa:

La aparición de la nueva agenda de derechos humanos, sexuales y reproductivos en el escenario internacional dio lugar a la emergencia de nuevas identidades que exigían reconocimiento como "minorías sexuales", con el fin de encajar en las posibilidades financieras de las agendas estatales e internacionales. Así, se reagruparon bajo la denominación de "diversidad sexual”, integrándose incluso a la heterosexualidad y perdiendo el sentido crítico a la sobre determinación del poder político de la heterosexualidad obligatoria. De este modo, se instalaron en una lucha conjunta por el derecho a la inclusión: la salud (VIH/SIDA), la legislación antidiscriminatoria, el derecho a la maternidad y la paternidad, el derecho al matrimonio y hasta los concursos de Mis Universo Gay... (2008, p. 71).

El sujeto moderno era un sujeto con una identidad determinada, fácil de controlar y disciplinado. En el siglo $\mathrm{xx}$ este sujeto explota, las identidades devienen, rompen, se autogeneran, abundan, y allí sería pertinente lo que Daniel Borrillo refiere como teoría queer del derecho: "Una teoría de la justicia individual que integra en el universo jurídico 
a todas las personas sin considerarlas en función de su sexo-génerosexualidad, categorías estas desprovistas de pertinencia jurídica" (2011, p. 32); pero no, desde los procesos de reconocimiento de derechos se le quiere atribuir nuevamente una identidad completa, cerrada, definitiva, con una esencia y características fundamentales que la constituyan, establecidas como verdades incuestionables, como dogmas, a partir de los cuales se validan unos parámetros permitidos para vivir la sexualidad, el amor, la familia, en franca coherencia con los valores ilustrados ontologizados. En este sentido,

los reglamentos estatales que regulan la adopción lesbiana y gay, así como las adopciones de familias monoparentales, no solo restringen dicha actividad, sino que se refieren a y refuerzan un ideal sobre cómo deben ser los padres, por ejemplo si deben tener un/a compañero/a y qué se considera como un/a compañero/a legítimo/a. Por lo tanto, los reglamentos (...) performan otra actividad que permanece, en su mayor parte, sin señalar: la producción de parámetros de persona, es decir, el hacer personas de acuerdo con normas abstractas que a la vez condicionan y exceden las vidas que hacen - y rompen. (Butler, 2006, p. 88).

Diferente a lo planteado por Pau López Clavel (2015), quien afirma que el matrimonio igualitario es un avance frente a la homofobia de Estado, considero que el reconocimiento de derechos de la población LGBTI en Colombia, de la diversidad sexual y de género, no ha implicado la superación de esa homofobia, que no es más que su diseño y funcionamiento desde la heteronormatividad reproductiva y sancionatoria de las expresiones de diversidad, posición que, como señala López C. (2015), puede ser cercana con las posiciones conservadoras. Ahora se trata de mecanismos no represivos del poder que controlan y regulan los cuerpos, las sexualidades y los géneros, disciplinándolos y haciendo que el sujeto de la democracia sea un sujeto sometido, "este sistema normativo o ideal regulatorio no es solo un poder represor que limita al sujeto, sino que es un poder productivo que le permite al sujeto llegar a ser” (Sabsay, 2011, p. 107), es un sujeto subjetivado. 
Pero en ese forcejeo hay expresiones de subjetividad que son molestas para aquella diversidad permitida y promovida en función de un orden sociosexual. El repudio de esas subjetividades que no entran en la diversidad se convierte en necesario para mantener el equilibrio en relación con la "normalidad sexual" a la que se dice hay que tender. Equilibrio, que retomando a Lemebel et al. (2019) es sospechoso, en la medida que ya no pelea, sino que sostiene "ese tipo de instituciones".

Entonces, ¿cuáles son las rutas para la igualdad?, ¿qué alternativas plantear para lograr un pacto de ciudadanía plena que no se base en la inclusión social y el asimilacionismo?

\section{Un nuevo pacto: disentir activa, colectiva y solidariamente}

Diversidad sexual y de género y disidencia sexual y de género son términos necesarios en términos teóricos y políticos para referirse a diferentes aspectos de un proceso que tiene como su centro la lucha por el reconocimiento pleno de los derechos sexuales y reproductivos como derechos humanos. (Núñez, 2011, p. 78).

Lo planteado hasta aquí no se trata de una oposición o rechazo a los avances logrados en la búsqueda de reconocimiento de la diversidad y orientados a superar la injusticia cultural, pero sí, desde un activismo académico crítico, de llamar la atención respecto a trampas que traen estos reconocimientos, que llevan a la perpetuación de los sistemas de dominación y subordinación, y sobre las exclusiones que generan, pero que exponerlo en voz alta puede no ajustarse a los cánones de lo "políticamente correcto", que a veces exige el contexto de la euforia que generan esos logros. Diversidad y disidencia son dos perspectivas que vistas, no de manera dicotómica, como señala Núñez, se refieren a diferentes aspectos e implican, como he señalado, diferentes ópticas y posicionamientos políticos. 
Etimológicamente la palabra disidencia viene del latín dissidentia, que descompuesta contiene el prefijo dis que tiene que ver con divergencia, separación; el verbo sidere - sentarse- y el sufijo tio, que indica acción y efecto (http://etimologias.dechile.net/?disidencia). Así las cosas, se puede asumir la disidencia como la acción y efecto de separarse, desavenir-se, romper, tomar distancia, sentar posición diferente. Esto ya plantea claras diferencias con incluirse, asimilarse, apropiar los valores y la moral hegemónica.

En la misma línea, retomo el abordaje que hace Gabriela González Ortuño a partir del concepto de disidir, que según el Diccionario de la lengua española es "separarse de la común doctrina, creencia o conducta". Esto implica que no se trata de un simple desacuerdo, sino de la intención de tomar distancia de lo establecido para buscar construir relaciones diversas” (González, 2016, p. 181). No es solo entonces tomar posición frente a, sino también construir relaciones con otros, otras y otres, en esa toma de posición. Por otra parte, Núñez Noriega lo plantea como,

ese momento de lucha, de oposición, de contestación cultural, social y política dentro del campo sexual (...) se refiere más bien a aquellas realidades sexuales y de género (identidades y prácticas) que disienten del modelo sexual y de género dominantes, que como ya vimos, es heterosexista y androcéntrico. (2011, pp. 76-77).

Sin embargo, y teniendo en cuenta lo planteado por el mismo Núñez (2011), es necesario ampliar su mirada cuando hablamos de realidades sexuales y de género, ampliación que se logra al señalar frente a qué se toma distancia y se sienta posición, esto es, frente al "patriarcado, la heterosexualidad obligatoria, el racismo, el clasismo y el neoliberalismo" (González, 2016, p. 82, nota 5), entre otros. Sistemas que operan y afectan nuestros cuerpos, que son centro del control, de las violencias y por tanto de la disidencia, en la medida que confrontan, rompen, se distancian de las verdades y relatos establecidos por ese entramado de sistemas que funcionan de manera articulada, para generar verdades 
acordes con el "modelo etnicista", heterosexual y dicotómico. La disidencia no pone su atención entonces en los procesos identitarios, sino en los sistemas que generan opresión y violencias sobre los cuerpos y el devenir de sus identidades.

La disidencia también hay que pensarla como la separación, distanciamiento y toma de posición frente a esa nueva "reontologización liberal" de la que habla Sabsay (2011) en relación con la homonormatividad. Es decir, disentir incluso del proyecto "gay" neoconservador y asimilacionista que impone una nueva moral asociada a la hegemónica y nueva jerarquía de cuerpos, géneros y sexualidades permitidas, que establece una nueva norma, donde "reafirmarse por fuera de la norma implicaría un ejercicio de disidencia” (Correa, 2017, p. 13, nota 1).

La disidencia se da así en la medida que aparecen y se visibilizan cuerpos y subjetividades que rompen con lo establecido como verdadero, como el deber ser, como el statu quo. Es decir, la disidencia aparece en la medida que se instalan las normas, los regímenes de verdad, lo normal, porque de manera vinculante se genera lo que no hace parte de esa verdad construida. En ese sentido,

seguir hablando desde la disidencia sexual, y no desde la "diversidad sexual”, expresa un posicionamiento político de resistencia a todo intento de "normalización" o integración a una sociedad donde los financiamientos pueden transformar el sentido real de los problemas sociales y modificar las metodologías de trabajo y, en consecuencia, también los discursos. (Mogrovejo, 2008, p. 71).

Los sujetos nos vemos abocados a estar subjetivados, es decir, a estar producidos por la acción de la norma, a vivir bajo la acción del imperio, que "está allí donde no pasa nada. En cualquier sitio donde esto funciona. Ahí donde reina la situación normal” (Tiqqun, 2013, p. 9). Allí, la disidencia puede y es ideal que viva un proceso de hacer conciencia de ser disidencia, asunto que se da en la medida que quien es disidente 
experimente las violencias que puedan surgir de su confrontación con la norma y la normalidad, con los sistemas de dominación, de tal manera que pueda tomar posición frente a estos. Para esto son necesarios los procesos de subjetivación que se puedan vivir, en los que cada cual pueda descubrir y nombrar su identidad, entendida como conciencia de la experiencia, para tomar posición crítica frente a la realidad y sus dinámicas, porque "no es lo mismo ser desigual (discriminada, minorizada, despreciada) que reconocerse diferente de quien emite y sacraliza el discurso del poder, porque una es capaz de ubicarse fuera de su sistema de operación” (Gargallo, 2008, p. 25).

Vista así, como lo señalé desde el inicio, la disidencia como posición política no es nueva, y uno de los mejores ejemplos de esto se puede observar en el contexto de las luchas por la liberación sexual en la segunda parte del siglo xx; para ello traigo este fragmento del manifiesto de la Liga Estudiantil Homófila, escrito en agosto de 1969 en New York, es decir, un mes después de las revueltas de Stonewall: "En consecuencia, declaramos nuestro apoyo como homosexuales o bisexuales a las luchas de los negros, las feministas, los hispanos, los indios, los hippies, los jóvenes, los estudiantes y otras víctimas de la opresión y los prejuicios (2009, p. 49).

Es decir, la disidencia sexual, de género y corporal, es una alternativa para el reencuentro entre las víctimas de las múltiples manifestaciones de opresión y violencias, constituidas en sujetos políticos que se encuentran para enfrentar los enemigos que les son comunes, los múltiples sistemas de dominación y frente a los cuales es importante tener claro que el objetivo ha de ser la transformación de las estructuras que estos producen y sostienen, y que allí, en esa reacción articulada, está nuestro potencial.

Ahí es cuando adquiere sentido la referencia a la solidaridad como estrategia, en el manifiesto de la Liga Estudiantil Homófila. Para disentir será necesario el diálogo y la articulación de procesos de lucha que se 
han dado de manera aislada y fragmentada por las políticas multiculturales que agudizaron procesos identitarios en el marco del neoliberalismo, con la consabida promoción de los derechos liberales, considerados como única alternativa o la más pertinente en las últimas décadas. Esto nos lleva a que la disidencia requiere de las herramientas de análisis desde la interseccionalidad, porque esta será efectiva desde el encuentro entre homosexuales, lesbianas, trans, bisexuales, negros, feministas, migrantes, pueblos originarios, jóvenes, estudiantes, las mujeres y las mayorías de hombres víctimas de la opresión y los prejuicios, que finalmente no somos tan diferentes, porque las víctimas de la opresión y los prejuicios tenemos enemigos comunes que enfrentar, como también lo denunciaba la Liga Estudiantil Homófila:

Nuestros enemigos: un sistema gubernamental implacable, represivo; una religión, una medicina y un mundo empresarial bien organizados, que no cambiarán mediante el diálogo o las apelaciones a la razón y la justicia, sino sólo por el poder y la fuerza. (2009, p. 49).

Veo entonces oportuno volver a citar a Nancy Fraser (2000) en sus reflexiones en torno a las políticas del reconocimiento, a partir del fortalecimiento de las identidades y su distanciamiento con la necesidad de la redistribución; esto, para recordar la necesidad imperante de que el reconocimiento incida en las condiciones materiales de existencia de los sujetos. Y es que el discurso promovido desde las transformaciones culturales ha desplazado la importancia de prestar atención a esas necesidades cotidianas. Ella denuncia que las políticas del reconocimiento han sido reducidas a las políticas de la identidad, de manera que cada individuo tiene que asumir características que le permitan la vinculación desde la normalización, así como se vio en el caso de las personas trans e intersexuales, porque si no, "la disidencia cultural y la experimentación son desalentadas, cuando no sencillamente equiparadas con la deslealtad” (Fraser, 2000, p. 60). 
Por esa ruta, es imperativo pensar la necesidad de retomar los puntos de encuentro entre quienes resultan más desfavorecidos y desfavorecidas ante el patriarcado, el heterosexismo, el androcentrismo, el racismo, el machismo y el capitalismo neoliberal; por eso la importancia de pensar las disidencias desde los cuerpos colonizados, racializados, empobrecidos, normatizados y que revientan las amarras que se les quiere imponer, porque como plantea Gabriela González, a partir de la experiencia de las lesbianas latinoamericanas autónomas y decoloniales,

vivir la negritud, la pobreza, el lesbianismo y en muchos casos la maternidad, las sitúan en una posición en la que las posibilidades de solidaridad con diferentes sectores oprimidos permiten pensar en espacios de lucha articulados a través de la diferencia. (2016, p. 185).

Así pues, el sujeto de la disidencia se constituye desde una mirada interseccional, no para renovar y establecer identidades, sino para generar encuentros, alianzas y acciones colectivas, orientadas a enfrentar los enemigos comunes ya reiteradamente señalados; así la disidencia es activa, colectiva y solidaria. Para ello, otro referente es el black feminism que comprendió la necesidad de

las alianzas y solidaridades que se deben anudar con otros movimientos sociales que defiende los intereses de los grupos minoritarios (Hooks, 2008). En este sentido, el sujeto político planteado por el black feminism y su crítica interseccional se define como una minoría que forma coalición con otras minorías. Su propuesta política se funda en la construcción de un movimiento social sensible a todos los tipos de opresión, exclusión y marginación: clasismo, sexismo, racismo, heterosexismo, sin priorizar ninguno de ellos de antemano, sino en forma contextual y situada. (Viveros, 2016, p. 13).

Aun así, no quiero dejar de señalar algunos sujetos en los cuales se podrían recoger características de ese sujeto colectivo. Sabsay (2011) señala a las mujeres trans en ejercicio de prostitución como nuevas 
excluidas o excluidas que se mantienen en esa situación, en relación con los derechos de la diversidad sexual; González (2016) se remite a señalar esta situación en el prostituto, pero también retoma una figura que yo había propuesto en 2008 en mi trabajo Homofobia y agresiones verbales, y es la figura de la "loca”, que relacionada con la locura, remite desde una perspectiva foucaultiana a lo irreductible a la norma, lo no asimilado por un sistema disciplinario o lo que escapa al poder normalizador. La loca posiblemente habita su libertad y en la medida en que la expresa se convierte en subversiva, cuando transgrede los símbolos culturales de lo masculino para habitar lo femenino. Pero no se trata de la loca como un universal, "se trata de la figura donde se cruzan las exclusiones de sexualidad, género, raza y pobreza” (González, 2016, p. 194), que es negada, desconocida, excluida por los sectores LGBTI, principalmente los gay de élite, con marcadas diferencias en sus intereses.

"En ellas no se solicita que se establezca el matrimonio entre personas del mismo sexo, ni una familia con padres del mismo sexo, porque encajar en las estructuras ya impuestas a las heterosexualidades no es su prioridad” (González, 2016, p. 192). "La loca” es una figura que permite reflejar la disidencia en acción y disidente incluso de los diversos incluidos y asimilados.

En esa acción de la disidencia, la disidencia activa, se mantiene cada vez más vigente la necesidad de una lectura y aplicación crítica del derecho y de la ciudadanía, que recoja las múltiples formas de subjetividad y no que la inclusión tenga que ser asumida como el acomodarse a las instituciones existentes como signo de igualdad, sino que más bien sea un pacto "donde el otro o la otra me importan en la convivencia y cuentan como ciudadanos” (Maffia, 2005, p. 22). Como los derechos siguen pensados para un sujeto atrapado en la dicotomía del género y en las instituciones patriarcales, se hace necesaria la generación de propuestas que permitan otras composiciones sociales, afectivas e identitarias. Porque repensar el derecho 
significa hacer de esta disciplina un instrumento transformador que desplace los actuales modelos sexuales, sociales, económicos y políticos hacia una convivencia humana basada en la aceptación de la otra persona como una legítima otra y en la colaboración como resultante de dicho respeto a la diversidad. (Facio y Fries, 1999, p. 7).

Finalmente, el lugar de la disidencia implica, de parte de quienes nos interesamos en la generación y difusión de conocimientos, ser también estudiosxs, académicxs, escritorxs, generadorxs de conocimiento, disidentes de nuestros campos de formación, que tradicionalmente han estado al servicio de los relatos hegemónicos androcéntricos, para producir entonces otros relatos, utilizar otras fuentes, o implementar otras metodologías y otras preguntas para las tradicionales. Para ello es necesario también, hacer uso de ese poder performativo del lenguaje, que es una necesidad ineludible y también puede y debe estar al servicio de la disidencia. El relato desde la academia debe confrontar los sistemas, relacionar sectores, leer la realidad desde los intereses de quienes están marginados de los lugares de dominación.

Así pues, la disidencia es una invitación a retomar apuestas más integrales por cambios estructurales de nuestra sociedad heterosexual, que como lo denunció Monique Wittig, "no es la sociedad que oprime solamente a las lesbianas y a los gays, oprime a muchos otros/diferentes, oprime a todas las mujeres y a numerosas categorías de hombres, a todos los que están en la situación de dominados” (2006, p. 53), llamadxs todxs a ser un gran bloque disidente y solidario.

\section{Referencias}

Borrillo, Daniel. (2011). Por una teoría queer del derecho de las personas y las familias. Direito, Estado e Sociedade, (39), 27-51.

Bustamante, Walter. (2008). Homofobia y agresiones verbales, la sanción por transgredir la masculinidad hegemónica, Colombia 1936-1980. Medellín: Todográficas Ltda. 
Butler, Judith. 2001. Sujetos de Sexo/Género/Deseo. En Judith Butler, El género en disputa. El feminismo y la subversión de la identidad (pp. 33-67). México: Paidós.

Butler, Judith. (2002). Cuerpos que importan. Sobre los límites materiales y discursivos del "sexo". Buenos Aires: Paidós.

Butler, Judith. (2004). El reglamento del género. En Judith Butler, Deshacer el género (pp. 67-88). Buenos Aires: Paidós.

Correa, Guillermo. (2017). Raros. Historia cultural de la homosexualidad en Medellín, 1890-1980. Medellín: Universidad de Antioquia.

Corte Constitucional de Colombia. Sentencia SU-214 de 2016 (M. P.: Alberto Rojas Ríos; abril 28 de 2016). Recuperada de http://www.corteconstitucional. gov.co/relatoria/2013/u-214-13.htm

Corte Constitucional de Colombia. Sentencia T-063 de 2015 (M. P.: María Victoria Calle Correa; febrero 13 de 2015). Recuperada de http://www.corteconstitucional.gov.co/RELATORIA/2015/T-063-15.htm

Corte Constitucional de Colombia. Sentencia T-450A de 2013 (M. P.: Mauricio González Cuervo; julio 16 de 2013). Recuperada de http://www.corteconstitucional.gov.co/relatoria/2013/t-450a-13.htm

Diccionario Etimológico Español en Línea. (s.f.). Etimología de disidencia. Recuperado de http://etimologias.dechile.net/?disidencia

Elpaís.com.co/Colprensa. (7 de abril de 2016). Corte Constitucional aprueba el matrimonio igualitario en Colombia. Recuperado de http://www.elpais. com.co/elpais/colombia/noticias/corte-constitucional-avala-matrimonioigualitario-colombia

Facio, Alda y Fries, Lorena (1999). Feminismo, género y patriarcado. En Alda Facio y Lorena Fries (Eds.), Género y derecho. Santiago de Chile: Ediciones La Morada.

Falquet, Jules. (2006). De la cama a la calle: perspectivas teóricas lésbico-feministas. Bogotá: Brecha Lésbica.

Fraser, Nancy. (2000). Nuevas reflexiones sobre el reconocimiento. New Left Review, (4), 55-68. 
García, Daniela. (16 de marzo de 2016). Entrevista de Walter Alonso Bustamante Tejada. Candidato a doctor en Estudios de Género, Universidad Nacional de Córdoba, Argentina.

Gargallo, Francesca. (2008). Las disidencias sexuales desde una mirada feminista. Trabajo Social, (18), 22-25.

González Ortuño, Gabriela. (Enero-junio, 2016). Teorías de la disidencia sexual: de contextos populares a usos elitistas. La teoría queer en América Latina frente a las y los pensadores de disidencia sexogénica. De Raíz Diversa, 3(5), 179-200. Recuperado de http://biblioteca.clacso.edu.ar/Mexico/ppelunam/20160630033827/8._Teorias_de_la_disidencia_sexual._-Gabriela_ Gonzalez_Ortuno.pdf

Hill Collins, Patricia. (2000). Black Feminist Thought: Knowledge, Consciousness and the Politics of Empowerment. Nueva York: Routledge.

Lemebel, Pedro; García, Macarena y Arroyo, Guido. (2019). No tengo amigos, tengo amores. Extractos de entrevistas a Pedro Lemebel. Chile: Alquimia Ediciones.

Liga Estudiantil Homófila. (2009). Un manifiesto radical: ¡El movimiento homófilo debe radicalizarse! (1969). En Rafael Manuel Mérida Jiménez (Coord.), Manifiestos gays, lesbianos y queer. Testimonios de una lucha (1969-1994) (pp. 49-50). Barcelona: Icaria.

López Clavel, Pau. (2015). Tres debates sobre la homonormativización de las identidades gay y lesbiana. Asparkía: Investigació Feminista, (26), 137-153.

López Romero, Marco Tulio. (2014). Lo gay y la derecha. En Ruth López y Pablo Bedoya (Eds.), Existir, habitar, resistir. Memoria histórica de las personas LGBTI en Medellín. Medellín: Alcaldía de Medellín/Universidad Nacional de Colombia.

Maffía, Diana. (2005). El contrato moral. En Elisa Carrió y Diana Maffía, Búsquedas de sentido para una nueva política. Buenos Aires: Paidós.

Mogrovejo, María Norma. (2008). Diversidad sexual, un concepto problemático. Trabajo Social, (18), 62-71.

Moreno Sánchez, Ángel y Pichardo Galán, José Ignacio. (2006). Homonormatividad y existencia sexual. Amistades peligrosas entre género y sexualidad. AIBR, Revista de Antropología Iberoamericana, 1(1), 143-156. 
Núñez Noriega, Guillermo. (2011). ¿Qué es la diversidad sexual? Reflexiones desde la academia y el movimiento ciudadano. Quito: Abya-Yala/Centro de Investigación en Alimentación y Desarrollo.

Olsen, Frances. (2000). El sexo del derecho. En Alicia Ruiz (Comp.), Indentidad femenina y discurso jurídico (pp. 137-156). Buenos Aires: Biblos.

Pateman, Carole. (1995). El contrato sexual. México: Anthropos.

Raymond, Janice. (1979). El imperio transexual. Boston: Beacon Press.

Sabsay, Leticia. (2011). Fronteras sexuales. Espacio urbano, cuerpos y ciudadanía. Buenos Aires: Paidós.

Shock, Susy. (Productora). (2019). Milonga queer [Video clip]. Traviarca [CD].

Tiqqun. (2013). Primeros materiales para una teoría de la jovencita. Buenos Aires: Editorial Hekht.

Viveros Vigoya, Mara. (Octubre de 2016). La interseccionalidad: una aproximación situada a la dominación. Debate Feminista, 52, 1-17. Recuperado de http://debatefeminista.cieg.unam.mx/df_ojs/index.php/debate_feminista/ article/view/2077/1871

West, Candance y Zimmerman, Don. (1999). Haciendo género. En Marysa Navarro y Catherine Stimpson (Comps.), Sexualidad, género y roles sexuales (pp. 109-144). Buenos Aires: Fondo de Cultura Económica.

Wittig, Monique. (2006). El pensamiento heterosexual. En Monique Wittig, El pensamiento heterosexual y otros ensayos (pp. 45-58). Barcelona: Egales. 